\title{
THE EFFECTS OF ENCOURAGEMENT ON LEARNING: HOW ENCOURAGEMENT AFFECTS THE QUALITY OF STUDENTS' PROGRESS DURING LEARNING LANGUAGE
}

\author{
Cakra Sagiarta Lee', Putu Chrisma Dewi ${ }^{2}$, Ni Luh Christine Prawita Sari Suyasa ${ }^{3}$, \\ Putu Chris Susanto ${ }^{4}$
}

Universitas Dhyana Pura

lee.cakra@gmail.com, chrismadewi@undhirabali.ac.id, christine.suyasa@undhirabali.ac.id, chris.susanto@undhirabali.ac.id

\begin{abstract}
The main purpose of this study is to investigate the effectiveness of encouragement on the quality of the students' learning progress during German learning. This research utilizes the mixed method of quantitative and qualitative as data gathering method. The case study that this study observes is the language preparation of the 9 (nine) selected students for student exchange program from SMPK 2 Harapan (Junior High School) Bali under blended learning. It focuses on analyzing the students' German learning progress both from their macro-skills and their inhibitions' factors. Throughout the study, it gives also encouraging feedback to every of the students and tries to help the students to cope with their inhibitions' factors. It takes interests in analyzing the effects of encouragement to students' self-efficacy which affects their motivation to learn foreign language and the effects on their scores based on the 4 (four) macro-skills.
\end{abstract}

Keywords: blended learning, effectiveness, encouragement, German, macro-skills

\section{INTRODUCTION}

Students' confidence during their language learning is really important in order to express their language skills. Through these expressions they apply their skills to communicate and to practice their new language. It is really important to develop confidence for the students in order for them to continuously practice themselves for the better and confidently use the new language without any hesitation regardless of their mistakes.

Vince Thomas Lombardi once said "Practice does not make perfect. Only perfect practice makes perfect". But to do perfect practice, a person must make a mistake and then analyze the mistake and correct it. But most of the people are hesitant to make mistakes which leads everyone to hide or not to utilize their skills. Although it is true, making mistakes is embarrassing. But what kind of a talent that is being hidden the entire time. This situation is tremendously affecting language learning. Whereas students learnt foreign languages throughout their education to prepare them for work internationally in this globalization era; they just simply couldn't utilize the language they have learnt whether it is speaking, listening, reading, or writing.

In a published journal namely "Speaking Difficulties Encountered by Young EFL Learners" the author stated that there are 3 (three) major difficulties that are affecting the students immensely 
during their study of learning English [1]. Those 3 (three) major difficulties are Linguistic Difficulties, Mother Tongue Use, and Inhibition. This study took interest to further analyze the $3^{\text {rd }}$ major point namely "Inhibition." According to MerriamWebster's dictionary, Inhibition is "an inner impediment to free activity, expression, or functioning: such as a mental process imposing restraint upon behavior or another mental process (such as a desire)" [2]

Encouragement plays an important role in this case against inhibition to embrace the students. According to another published journal "The Tools of Encouragement" the author described that "Encouragement is positive feedback that focuses primarily on effort or improvement rather than on outcomes. ... With encouragement, a child feels worthwhile and appreciated regardless of the results he or she achieves [3]." This study also had the same belief that through encouragement students will have the courage to face mistakes and through that mistake it is easier to correct them. Thus, revealing a better study case instead of just relying on teaching without any dynamic feedback from the students and the teachers. The preparation of German Language for SMPK 2 Harapan (Junior High School) students who were scheduled to participate in a short exchange student must be able to show his/her confidence especially when learning mistakes often occurred.

Therefore, this study aimed to find the effectiveness of encouragement during language learning. This research was conducted during the preparation of Indonesian students from SMPK2 Harapan (Junior High School) for their student exchange program Bali-Brunsbüttel. Through this research, this study expected that the students from SMPK2 Harapan (Junior High School) would use the German skills they have learnt in Indonesia effectively and uninterrupted by the inhibitions.

\section{METHOD}

The author conducted the mix method of quantitative and qualitative. The reason why this research combined these two methods was to find a perfect measurement that could be measured and reliable as the result of this study. In this study, the quantitative method was conducted through google forms platform or direct meeting if the main German language instructor decided to conduct an offline meeting. The lecturers spread the exercises which were designed after the four (4) language macro-skills (reading, writing, speaking, and listening) as a measurement of their true capabilities which the author made the exercises to be more compact by combining the macro-skills in the exercises instead of just focusing per macro-skills to meet the duration, safety, and effectiveness of the study itself under this semester's requirements and current situation by utilizing technology and strategies to deliver the exercises [4, pp. 47-48]. Meanwhile, the qualitative method was spread through google forms and WhatsApp platform in a form of questionnaires or feedback in order to collect their perspectives towards the utilization of German language and helped them cope with their anxieties and hesitations and kept them in task throughout the study of German language [5]. The qualitative method was done after the quantitative method was utilized in order to deepen the understanding and interpretation of the results. There were 3 (three) procedures that were conducted in this study. At the very beginning of the study, the lecturers spread the exercises to the students along with some questionnaires and some encouraging feedback to the students. Second, the author would collect the results of the students' works and give some encouraging feedback to the students through WhatsApp. Throughout this process also, the author gave encouragement and helps to some of the students who had trouble or obstacles during the completion of their study through WhatsApp private messages to make it easier for the students to discuss their problem. Lastly, the first and last data would be compared in order to conclude the interpretation of the study's results. The author would analyze the data through charts that were produced by the google forms platform and based on the rubrics that were made for the purpose of this study. 


\section{RESULT AND DISCUSSION}

The study finds quite promising results both on the exercises of the macro-skills that the students have done and, on their tendencies, based on their answers of the questionnaires and private discussions towards the German language itself that the students have filled and discussed. In this study, the exercises' design is more compact and accelerated to meet the requirements of study's duration. The results of their macro-skills and their inhibition factors are as follows:

\section{DEMOGRAPHICS}

The study began in 2021 with 9 students, ages $14-15$, from $8^{\text {th }}-9^{\text {th }}$ graders of SMPK 2 Harapan (Junior High School) who participated in the student exchange program under a blended learning situation due to COVID-19 pandemic. The school had made a thorough selection for the students who could participate in the program itself through capabilities (based on academic achievements, and language capabilities,) general knowledge of Germany and psychological tests. There were in total 7 females and 2 males' students who passed the qualification and they had learnt some basic German from their school first.

\section{WRITING \& READING}

Student's writing capability is really important to base their language skill before continuing to speaking and listening. Writing and reading are related to each other and it's linear throughout the learning process [6, p. 528], [7, p. 29]. Reading in this study is the ability to comprehend certain written object accurately and quickly whereas writing is the ability to communicate ideas through handwriting or typing [8, p. 1]. This study combines reading and writing together in order to focally improve both capabilities. The students write letters, describe something and even improve their grammar comprehension by combining these two subjects.
Table 1-WRITING \& READING SCORES

\begin{tabular}{cccccc}
\hline & Activity \#1 & Activity \#2 & \multicolumn{2}{c}{ Activity \#3 } & Activity \#4 \\
\hline Student 1 & 83 & 83 & 100 & 86 & 100 \\
\hline Student 2 & 83 & 83 & 93 & 93 & 100 \\
\hline Student 3 & 86 & 93 & 90 & 93 & 100 \\
\hline Student 4 & 83 & 86 & 83 & 86 & 86 \\
\hline Student 5 & 80 & 86 & 90 & 83 & 100 \\
\hline Student 6 & 80 & 83 & 100 & 100 & 86 \\
\hline Student 7 & 83 & 86 & 83 & 100 & 90 \\
\hline Student 8 & 86 & 86 & 100 & 93 & 93 \\
\hline Student 9 & 83 & 100 & 93 & 86 & 0 \\
\hline
\end{tabular}

The study finds out that most of the students improve their grammar and could express themselves better through writing as their assignments are improving in contents' size and within time they make less and less grammatical errors. This study scores their writing and reading capabilities through a self-made rubric [Appendix A].

Encouragement's effectiveness can be seen through the will of the students. Despite of the status of the study itself which is not their passing grades as explained in the limitations of this study. Students can find the will to learn more through the study and manage to find improvements within time in grammatical comprehension. The study finds also that students' grammatical errors must not be very crucial to take as they are still learning. However, a further guidance to correct their errors is really important in writing such as correcting grammatical errors. It is important to not pressure them if they make such errors to make them not producing any discouragement or inhibition in foreign language learning. Another good influence such as what Bob Ross always said that "there are no mistakes, just happy little accidents" can be really positive throughout the study.

Unfortunately, one of the students can't pass one of the activities' assignment due to lack of involvement throughout the study. Despite that, the study finds that their improvement is quite promising from first assignment to the latest one. The lack of involvement would be described thoroughly in inhibition factors discussion.

\section{SPEAKING, LISTENING, READING \& SELF EFFICACY}

Speaking and listening are both intertwined due to the relationship that based them as to express and to comprehend [7, p. 29]. Listening and 
speaking require also self-efficacy which is the amount of confidence that the students have in order to execute their ability based on their intentions which in this study is the execution of expressions in a vocal way [9, p. 1465]. This study also includes reading comprehension as another factor to scale the students' capability in order to find out the level of comprehension that the students have for the assignment. Students have to describe certain topic that they have chosen, and describe about a video, lastly in an offline meeting they have to introduce their partner that the lecturer has chosen.

Table 1-SPEAKING, LISTENING, READING \& SELF EFFICACY SCORES
\begin{tabular}{cccc}
\hline & Activity \#1 & Activity \#2 & Activity \#3 \\
\hline Student 1 & 78 & 84 & 0 \\
\hline Student 2 & 86 & 90 & 96 \\
\hline Student 3 & 88 & 92 & 92 \\
\hline Student 4 & 80 & 84 & 88 \\
\hline Student 5 & 96 & 96 & 82 \\
\hline Student 6 & 78 & 92 & 82 \\
\hline Student 7 & 0 & 0 & 86 \\
\hline Student 8 & 86 & 82 & 82 \\
\hline Student 9 & 0 & 0 & 80 \\
\hline
\end{tabular}

The study finds a gradually improvement from the students when it comes to speaking, listening, and reading skills that partly influenced by self-efficacy and encouragement. However, the road is not always so smooth for the students. Some of the students encounter downfall that could be influenced by many things. The last activity is describing partner in front of the class which could be the reason why some students encounter a degradation of self-efficacy yet some still have a really huge motivation to manage their performance stable or to improve it. In this study, speaking mistakes such as pronunciation and grammar give no punishment or negative feedback to not make them discouraged and making them carry future inhibitions in speaking. However, further guidance to correct their mistakes is the most important such as correcting pronunciation.

When it comes to listening and reading skills, it is clear that the students have no problem at all as they can understand clearly the main objective of assignment 2 (two) which is describing German video. The assignments that the lecturers have given are all written in German which also requires a good comprehension level in terms of reading. In this study, lecturer scores the students' assignment by utilizing a self-made rubric [Appendix B].

The lack of scoring from some of the students is due to lack of involvement when it comes to passing their assignments, whereas one of the students has personal matter that makes one of them couldn't attend the last offline class. Encouragement effectiveness in this section would be explained thoroughly in the inhibition factors section as the study finds a really unique finding that deserves its independent explanation.

\section{READING \& LISTENING}

This is the last part of this study's analysis for macro-skills which is more focused on reading and listening skills. Combining reading and listening somehow creates a really big spark that indicates the two of them are both perfectly fit and match up in a high rate, but the two are not perfect, because some of the disciplines of both comprehensions share the equal concepts, but both are not entirely the same [10, p. 1750]. This study finds out a quite unique matchup between both comprehensions. All in all, for both comprehensions in this section, the assignments are answering multiple choice questions based on the comprehension of the students on German videos. The scores are automatically generated by google forms without any need for a rubric.

Table 1-READING \& LISTENING SCORES
\begin{tabular}{ccc}
\hline & Activity \#1 & Activity \#2 \\
\cline { 2 - 4 } & \multicolumn{3}{c}{ Student 1 } & 100 \\
\hline Student 2 & 100 & 90 \\
\hline Student 3 & 90 & 100 \\
\hline Student 4 & 90 & 80 \\
\hline Student 5 & 80 & 100 \\
\hline Student 6 & 80 & 100 \\
\hline Student 7 & 90 & 90 \\
\hline Student 8 & 80 & 80 \\
\hline Student 9 & 0 & 0 \\
\hline
\end{tabular}

This study finds some quite stable results from the students. This shows that the students have a good listening comprehension because both assignments have the answer keys from the videos. Some students achieve a little bit of improvement that makes their score perfect.

Unfortunately for one of the students, there is not much of explanation as the involvement rate 
from one particular student is shallow. The situation from one of the students will have some explanation in inhibition factors section. Throughout this study, it is clear that the study finds out that the students have the capability to utilize their German language. However, this study is not perfect and the students still require further guidance. The study encourages every personnel who participates in guiding the students throughout their study in German language to further guide them in every occasion and to encourage them to utilize their German skills without minding the fear of making mistakes.

\section{INHIBITION FACTORS}

Throughout the learning process of the students, the study finds also some unique occasions that describe students' inhibitions. There are many inhibitions such as lack of self-efficacy and environmental influences that can damage the students' learning progress. However, this study manages to improve their will and self-efficacy through encouraging study which is the base of this study. In this section, the study will describe some inhibitions and encouraging methods that the study itself faces and copes.

First of all, the study finds out in the early time of this research that most of the students have their self-efficacy issues. They find lack of selfefficacy to utilize their German language and most of the students find more confidence by relying themselves on English language despite of Germany is mostly German speaking country due to most of the citizen of Germany are elderly. There are obviously few younger people that can speak good English but still it will be an advantage to really utilize German language in their land.
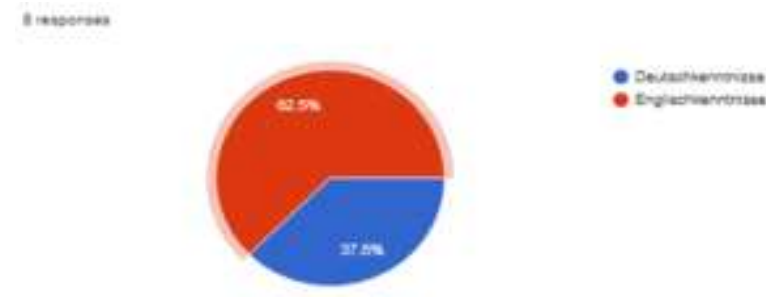

Figure 1-Would you like to utilize your German skill or simply your English skill in Germany?
In accordance with the result of the first survey from April $9^{\text {th }} 2021,5$ out of the 8 students find out that they have more confidence to speak in English instead of German if they are in Germany. In conclusion why the 5 students have more confidence in English is due to the reason that they have learnt English for a long time already and they find that they are rather more comfortable and more used to English. However, the 3 out of 8 students find out that since they are the participants in German-Indonesian student exchange they would like to learn and utilize German language hopefully they can master it. One of the reasons also aside of their awareness that they are in German-Indonesian student exchange program is that they love to try new challenges and to learn many languages. The interests of these 3 students are the most important that the program should encourage more and hopefully could share the same interests to the other students as well. In response of the 5 students who find that they feel better by utilizing English instead of German, it shows that their situation is simply the same of what the chapter 3 in a book Teaching Through Encouragement by Robert J. Martin has stated that students in certain occasion would have the feeling to feel fear of humiliation despite of their good grades and their true capability that makes them want to avoid humiliation and feel lack of self-efficacy on themselves [11, p. 32]. Certainly, the students who participate this program are not merely normal students, they are accordingly students with rank and good grades and according to the macro-skills their German capability is exquisitely good. However, through the fear of humiliation most of the students feel rest assured to use English instead of German. They rather avoid mistakes that makes them feel humiliated than learning it.

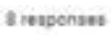


Figure 2-Although German is a new challenge for you, do you have the confidence, that you could master this language?

Aside of that, the study finds in the same survey that 6 out of 8 students find that they have no assurance whether they can master German language or not. Despite that, their explanations are simply because German is complicated and hard, but if they want to put their will and learn about it, they simply can master it. All in all, they still put "maybe" as their option. This is part of the limitation of this study, the cultural behavior when students have the feeling that they could master something but they still feel not sure about it. They are being low key about their self-efficacy. Student 7 also mention that mastering German language is possible but it takes time and efforts, yet the answer still "maybe" for student 7. The answer shows possibility and positive answer yet the bias goes straight to "maybe". Whereas in contrast of that situation, there are 2 out of 8 students answer "yes" and positively answer that they could master the German language despite of the difficulty of the language itself.

To cope with the uncertainty of the students, this study responses through an exercise which is the first activity of speaking a week after their survey. The study applies one of the concepts that the book Teaching Through Encouragement recommends to cope with the fear of humiliation of the students which is to ignore mistakes of the students to encourage them to cope with their fear of failure. Right after the exercise, they have to answer another survey which results a surprising turnabout for this study.

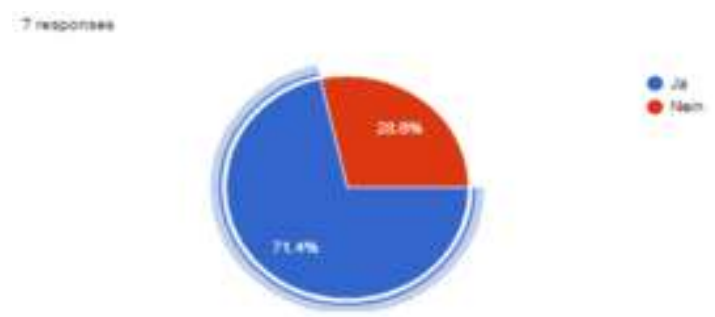

Figure 3-Have you learnt the self-efficacy through this assignment to speak German?
In accordance with the result of the last survey in April 16 ${ }^{\text {th }} 2021,5$ out of 7 students give responses that they have the self-efficacy to speak German after they collect their assignments. This result is not only a mere blind test, but the theory behind this result is actually from the same book Teaching Through Encouragement. When it comes to encouragement, it is normal to think of praises or creating easy tasks to improve students' interests. However, in this study, the task is not even easy for newbies, nor the students will have direct praises right after. Encouragement comes also through ignoring students' mistakes which sounds ridiculous at first but the results come out very impressive, it is due to these students despite of their grades and ranks they are still beginner in German language, but by wasting the time just to correct their mistakes will create discouragements and inhibitions either in trying or facing their mistakes, simply like newbie performers who must perform through and ignore their mistakes until their performances reach their ends [11, pp. 38-39]. However, it is not also wrong, that praises and corrections are exist throughout this study. Although, the portions of praises and corrections are not too much as the book Teaching Through Encouragement states also that praise can be encouraging, but it can contribute also to anxiety and fear of failure, and people tend to oversell praises as a technique to increase motivations, although it can be still manipulative and underhanded [11, p. 40]. This study takes the perspective that praises should be honest, direct, and oversold which results "appreciation" as the better term to praise their works. In this study, corrections are not also too much, the study does not see students' mistakes as mistakes that sounds pressuring and demanding for good performance, but more like confusion that must be corrected to keep the students not only feel easier to see their errors but also to make them feel less pressured when they are getting corrections [11, p. 36].

However, this study doesn't only find positive results as there are also many factors of limitations that inhibit the study's processes. Throughout this study, there are some students who have lack of involvement which makes it difficult for the study to find its effectiveness. The sample size is rather too small for the study that 
unfortunately makes the study which is not the students' passing grade subject has little audiences when some of the students forget their tasks or bothered by outer inhibitions. One study case that is worth to mention is from one of the students. The study finds that one of the students has unfortunately a discouraging environment for learning German. The discouraging environment which makes them suffer is not merely lack of facility for learning but more into the language of discouragement and anxiety of the certainty of the program itself. In this study, one of them states that throughout the learning process, they face many teasing from surroundings which makes one of them has little self-efficacy that leads also to lack of interests and cooperative manner for studying German language. In the book Teaching Through Encouragement, the study finds that any form of language that belittle somebody's self-efficacy to make them avoid their responsibility, turning them away from learning, making them not competent and even making them not cooperative is the language of discouragement [11, p. 69]. This however is not the field of the study to complain and further to work on. This study can only encourage the students to make them feel better and to ignore such inhibitor in hope they will have the motivation to learn but this study is not for stopping the inhibitor itself. In response to the study's efforts, that one of the students find a little of motivation that makes them accomplish some writing tasks. However, this is not enough so long the inhibitor still influences their motivation. Thus, the study results some of the scoring gone missing.

\section{CONCLUSION}

This study observes the gradual increment of their macro-skills and their paradigm shifts of their self-efficacy throughout the entire processes. There are many inhibitions that can affect the students' performance both internally or externally. From such simple teasing which is language of discouragement and even the comfort zone of using long taught language such as English. The study results that these factors affect the students' selfefficacy from out of the sight. Oversold praises and frequently correcting mistakes couldn't be the best answer to help students' learning progress. However, by ignoring mistakes where it is appropriate can encourage students to try even more and that what makes students feel not discouraged. Through good self-efficacy, students have the will to challenge themselves and express themselves even more confidently. Hence, making the students more productive and motivated to learn instead of carrying fear of failure. Perfect practice makes perfect and a perfect practice requires learning from mistakes. However, mistakes should not be considered as something punishing and demanding. Therefore, the study finds that encouragement affects students' self-efficacy and motivation to learn.

\section{ACKNOWLEDGEMENT}

Writers would like to thank you Universitas Dhyana Pura through LPPM which has funded this project. Also, to all teachers and students of SMPK 2 Harapan who have helped us during this project. God bless you abundantly.

\section{REFERENCES}

[1] S. Al Hosni, "Speaking Difficulties Encountered by Young EFL Learners," vol. 2, p. 26, Jun. 2014.

[2] "Definition of INHIBITION," Merriam Webster. Accessed: Jun. 04, 2021. [Online]. Available: https://www.merriamwebster.com/dictionary/inhibition

[3] T. Evans, "The Tools of Encouragement," Reaching Today's Youth: The Community Circle of Caring Journal, vol. 1, no. 2, p. 1, 1997.

[4] P. Panagiotidis, P. Krystalli, and P. Arvanitis, "Technology as a Motivational Factor in Foreign Language Learning," EJED, vol. 1, no. 3, pp. 47-48, Dec. 2018, doi: 10.26417/ejed.v1i3.p4352.

[5] A. Isman, A. a, and F. Altinay, "Roles of the Students and Teachers in Distance Education," The Turkish Online Journal of Distance Education, vol. 5, Oct. 2004. https://www.itdl.org/Journal/May_04/article05.htm 
[6] R. Schoonen, "Are reading and writing building on the same skills? The relationship between reading and writing in L1 and EFL," Read Writ, vol. 32, no. 3, pp. 511-535, Mar. 2019, doi: 10.1007/s11145-018-9874-1.

[7] L. M. Sadiku, "The Importance of Four Skills Reading, Speaking, Writing, Listening in a Lesson Hour," EJLS, vol. 1, no. 1, pp. 29-31, Apr. 2015, doi: 10.26417/ejls.v1i1.p29-31.

[8] B. Miller, P. McCardle, and R. Long, The Reading-Writing Connection. International Reading Association, 2012.

[9] S. Demir, "An Evaluation of Oral Language: The Relationship between Listening, Speaking and Self-Efficacy," Universal Journal of
Educational Research, vol. 5, no. 9, pp. 1457-1467, 2017.

[10] M. Wolf, M. Muijselaar, A. Boonstra, and E. Bree, "The relationship between reading and listening comprehension: shared and modalityspecific components," Reading and Writing, vol. 32, pp. 1747-1767, Sep. 2019, doi: 10.1007/s11145-018-9924-8.

[11]R. J. Martin, Teaching Through Encouragement: Techniques to help students learn. Englewood Cliffs, New Jersey 07632: PrenticeHall, Inc., 1980. 